\title{
Correction to: Enhanced L-Dopa production from elicited cell suspension culture of Hybanthus enneaspermus (L.) F. Muell
}

\author{
Selvam Sathish ${ }^{1}$. Venkatachalam Vasudevan ${ }^{1}$. Sivabalan Karthik ${ }^{1}$. Gadamchetty Pavan ${ }^{1}$. \\ Markandan Manickavasagam ${ }^{1}$
}

Published online: 3 October 2019

(c) Korean Society for Plant Biotechnology 2019

\section{Correction to: Plant Biotechnology Reports https://doi.org/10.1007/s11816-019-00555-y}

In the original publication of the article, the name of the corresponding author was published incorrectly as Markandan Manickavasagm. The correct name is Markandan Manickavasagam.

The original article has been updated.

Publisher's Note Springer Nature remains neutral with regard to jurisdictional claims in published maps and institutional affiliations.

The original article can be found online at https://doi.org/10.1007/ s11816-019-00555-y.

Markandan Manickavasagam

manickbiotech@gmail.com

1 Department of Biotechnology, Bharathidasan University,

Tiruchirappalli 620 024, Tamil Nadu, India 